J. Dairy Sci. 92:913-921

doi:10.3168/jds.2008-1180

(c) American Dairy Science Association, 2009.

\title{
Interactions of vacuum, b-phase duration, and liner compression on milk flow rates in dairy cows
}

\author{
R. D. Bade, ${ }^{\star}$ D. J. Reinemann, ${ }^{*} \dagger^{1}$ M. Zucali, $\neq$ P. L. Ruegg, ${ }^{\star}$ and P. D. Thompson $† \S$ \\ ${ }^{*}$ Department of Dairy Science, University of Wisconsin, Madison 53706 \\ †Department of Biological Systems Engineering, University of Wisconsin, Madison 53706 \\ ‡Dipartimento di Scienze Animali, sez. Zootecnica, Facoltá di Agraria, Universitá degli Studi di Milano, via Celoria 2, 20133 Milano, Italy \\ §Bou-Matic, 1919 S. Stoughton Road, Madison, WI 53716
}

\begin{abstract}
Vacuum, b-phase duration, and liner compression are 3 milking machine factors that affect peak milk flow rate; however, extreme values of these factors can also have negative effects on teat tissue health. The main and interactive effects of vacuum, b-phase duration, and liner compression on peak milk flow rate were studied by independently controlling these causal variables over a wide range of settings, using a central composite experimental design (42 to $53 \mathrm{kPa}$ of system vacuum, 220 to $800 \mathrm{~ms}$ of b-phase, and residual vacuum for massage of 16 to $30 \mathrm{kPa}$; corresponding to a liner compression of 8 to $14 \mathrm{kPa}$ ). The results of this study indicated that increasing the vacuum and b-phase duration always increased peak milk flow rate (no relative maximum was reached); however, the rate of increase of flow rate decreased as the vacuum and b-phase were increased. Increasing the liner compression also increased peak flow rates, with an increasing effect at greater vacuum. The interaction between vacuum and liner compression and the lack of interaction between b-phase and liner compression indicate that for a corresponding increase in peak milk flow rate, increasing the b-phase produced less teat-end tissue congestion than increasing the vacuum. The effect of milking vacuum on peak milk flow rate was smaller than that reported in previous studies, probably because of the independent adjustment of milking vacuum and liner compression used in this study. The effect of b-phase duration on peak milk flow was also smaller in this study than in previous studies, probably because of the independent adjustment of b-phase and d-phase durations used in this study.
\end{abstract}

Key words: vacuum, b-phase duration, pulsation, liner compression

Received March 14, 2008.

Accepted October 23, 2008.

${ }^{1}$ Corresponding author: djreinem@wisc.edu

\section{INTRODUCTION}

For most of the past century, vacuum and the duration of the b-phase of pulsation (as determined by pulsation rate and ratio) have been regarded as the primary machine factors influencing peak milk flow rate (PMF) and milking speed. It is widely accepted that both PMF and milking speed increase as milking vacuum is raised (Smith and Petersen, 1946; Baxter et al., 1950; Stewart and Schultz, 1958; Clough, 1972; Rasmussen and Madsen, 2000; Spencer and Rogers, 2004; Spencer et al., 2007). Peak milk flow rate and milking speed increased as the b-phase of pulsation was lengthened to approximately $600 \mathrm{~ms}$ (Clough, 1972; Spencer et al., 2007), but decreased in one study when the b-phase was increased further to $750 \mathrm{~ms}$ (Clough, 1972).

Increasing the vacuum and the b-phase (by changing either pulsation rate or ratio) increased teat congestion, as reflected by changes in teat wall thickness after milking, measured by using skin-fold calipers (Hamann, 1990; Hamann et al., 1993) or ultrasonic images (Neijenhuis et al., 2001; Gleeson et al., 2004; Vinitchaikul and Suriyasathaporn, 2007). Hamann and Mein (1996) concluded that a d-phase duration of at least $150 \mathrm{~ms}$ was enough to relieve congestion and that greater $\mathrm{d}$ phase durations resulted in little further decrease in congestion or increase in milk flow rate. A limitation of most of these pulsation studies is that the method used to lengthen the b-phase usually resulted in a concomitant shortening of the d-phase of pulsation.

Machine-induced congestion of teat tissues is relieved if liner compression (LC) during the d-phase of the pulsation cycle is of adequate magnitude and duration (Williams and Mein, 1982). Congestion that develops in the liner-open phase during the peak milk flow-rate period of milking but that is not relieved by the available LC will have a direct influence on PMF (Williams and Mein, 1982). Liner compression is a function of the physical dimensions of the liner, primarily wall thickness; the material properties of the liner, which change with time and use; liner mounting tension; and the pressure 
difference across the liner during the d-phase, which is affected by the milking vacuum (Mein et al., 2003). In a typical milking system, increasing the milking vacuum will also increase LC. One previous study that used independent adjustment of $\mathrm{LC}$ and milking vacuum reported that increased LC resulted in increased PMF (Williams et al., 1981); however, the b-phase was far in excess of the practical duration for milking and was not varied. When LC is adjusted either by changing the liner type or by the experimental method described by Williams et al. (1981), the b-phase and d-phase are also changed. Mein et al. (1987) predicted that LC equal to the mean arterial pressure of approximately $12 \mathrm{kPa}$ would be sufficient to relieve congestion and that additional LC would provide no additional benefit. In a later review, Mein et al. (2003) postulated that the LC required to relieve congestion was related to the milking vacuum, with greater $\mathrm{LC}$ being required at greater vacuum.

The role of $\mathrm{LC}$ in reducing teat tissue congestion during milking, and thereby influencing PMF and milking speed, has become clearer in the last $20 \mathrm{yr}$ (Thomas et al., 1991; Davis et al., 2000; Gleeson et al., 2004; Mein et al., 2004). However, such studies have typically used the same liner at different vacuums or different liners at the same vacuum. These methods lack independent control of milking vacuum and LC and therefore cannot separate the main effects of individual variables or correctly assess the interaction between these 2 important aspects of milking.

The primary objective of this study was to quantify the milking machine effects of vacuum, b-phase, and LC on milk flow rates to gain a better understanding of the physiological responses of teat tissues to machine milking. This study was designed to control these 3 causal variables independently over a broad range so that both main and interaction effects could be estimated. Our primary interest was in the effects of vacuum, b-phase, and LC on PMF, but we also measured average milk flow rate (AMF) over the entire milking to gain further insight into the influence of these causal variables during the low-flow period of milking.

\section{MATERIALS AND METHODS}

\section{Milking Facilities and Procedures}

This experiment was performed at the University of Wisconsin-Madison, low-level milkline, milking parlor. Treatments were applied during the p.m. milkings, allowing the a.m. milkings to reduce any possible carryover effects. The milking parlor operators used consistent preparation procedures for the duration of the experiment that consisted of predip application, manual forestripping, cleaning the udder with cloth towels, and then unit attachment. The resulting total premilking tactile stimulation was approximately 25 $\mathrm{s}$, with a preparation lag time (time from the end of preparation to the attachment of the first teat cup) of approximately $60 \mathrm{~s}$. Researchers were present at each p.m. milking to ensure consistency of the preparation routine, accuracy of data collection, and accuracy of cow identification.

Automatic cluster removers were set at a flow threshold of $0.6 \mathrm{~kg} / \mathrm{min}$ and a detachment delay of $3 \mathrm{~s}$. Milk flow meters were installed at each milking stall during the test period milkings (Lactocorder, WMB AG, Balgach, Switzerland). The a.m. milkings used the preexperimental milking system vacuum $(44.5 \mathrm{kPa})$, pulsation rate (60 cycles/min), and pulsation ratio $(60: 40 ;$ a-phase $=161 \mathrm{~ms}$, b-phase $=443 \mathrm{~ms}$, c-phase $=173 \mathrm{~ms}$, d-phase $=222 \mathrm{~ms}$ ). The PMF data used for this analysis were as reported by the milk flow meter and were defined as the maximum observed milk flow rate from all 4 teats in any 11.2-s interval during the milking. Average milk flow rate was taken as the total milk yield per milking divided by the total machine-on time.

Milking system vacuum was adjusted at the regulator and confirmed with a calibrated vacuum gauge. Wet tests were performed with an artificial udder to determine the relationship between the system vacuum and average claw vacuum at various water flow rates. This relationship was linear and is described by the equation

$$
\begin{gathered}
\text { Average claw vacuum }(\mathrm{kPa})= \\
{[0.97 \times \text { milking system vacuum }(\mathrm{kPa})]} \\
-[1.03 \times \text { milk flow rate }(\mathrm{kg} / \mathrm{min})] .
\end{gathered}
$$

Pulsation rate and ratio were adjusted so that the b-phase corresponded to the treatment value while the d-phase was maintained at $250 \mathrm{~ms}$ for all treatments. The duration of the d-phase was chosen to be substantially longer than the International Organization for Standardization (Geneva, Switzerland) minimum of $150 \mathrm{~ms}$, with the intent that the d-phase would not be a limiting factor in congestive relief for any of the treatments. The a-phase and c-phase of pulsation averaged 161 and $173 \mathrm{~ms}$, respectively, and showed minimal changes across the range of experimental treatments. These changes were taken into account when adjusting the pulsation rate and ratio for each treatment, and the b-phase and d-phase durations were confirmed with a dry test of pulsation before each treatment.

New liners were installed in the milking parlor $3 \mathrm{~d}$ before the beginning of the experiment. The liners used 
for the study were commercial nitrile rubber liners, round in shape, with a mouthpiece opening diameter and midbarrel diameter of $19 \mathrm{~mm}$, a wall thickness of $2.7 \mathrm{~mm}$, and a touch point (vacuum required to collapse the liner and allow opposing walls to touch) of $13 \mathrm{kPa}$ (Magnum 300, Bou-Matic, Madison, WI). The touch point of the liners was measured daily and did not change significantly during the experiment.

The residual vacuum for massage (RVM) is the vacuum difference across the closed liner during the d-phase of pulsation minus the touch point. The interior of the liner is exposed to the claw vacuum during the entire pulsation cycle. The exterior of the liner is exposed to the pulsation chamber vacuum, which alternates between the system vacuum (during the bphase) and atmospheric pressure (during the d-phase). A milking liner applies little or no compression to the teat at pressure differences across the liner up to the touch point. As the pressure difference across the liner is increased above the touch point, the compression applied to the teat increases. Measurements were performed on the liners used for this study to determine the relationship between RVM and LC. Liner compression was measured for 10 cows by using the beginning of milk flow method described by Mein et al. (2003). Residual vacuum for massage was linearly correlated with the 10-cow average LC according to the equation:

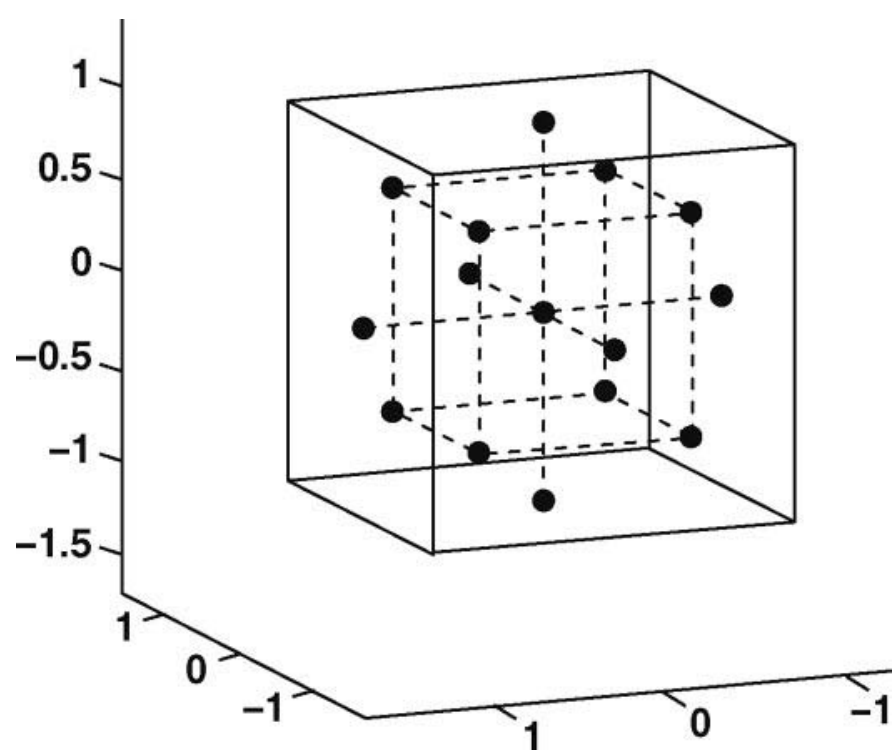

Figure 1. Graphical illustration of the 3-dimensional experimental space of an inscribed central composite design. The values of the causal variables are indicated on a relative scale with $+1 /-1$ corresponding to the experimental range of each causal variable. The design is a composite of 3 separate components: the center point, the 8 corners of an inscribed cube forming a 2-level full factorial design, and the star points in the center of each of the 6 faces, representing the maximum and minimum values used for each causal variable.
$\mathrm{LC}=0.83+(0.44 \times \mathrm{RVM})$. In a conventional milking system, the pulsation chamber is opened to air at atmospheric pressure during the d-phase. In this experiment, RVM was controlled by adjusting the vacuum in the pulsation chamber during the d-phase of pulsation as described by Williams et al. (1981).

\section{Test Subjects}

Test subjects were 77 Holstein cows milked twice per day at equal intervals. The average parity of the cows was 2.4, with a median of 2 and a range of 1 to 6 . The stage of lactation for the experimental cows studied ranged from 19 to 680 DIM, with an average of 250 DIM. Milk production over the 23-d experimental period averaged $27 \mathrm{~kg} / \mathrm{cow}$ per day and ranged from 12 to $50 \mathrm{~kg} / \mathrm{cow}$ per day.

\section{Experimental Design and Statistical Analysis}

An inscribed central composite experimental design (CCD) was chosen for this study (National Institute of Standards and Technology, 2006; SAS Institute, 2008; Figure 1). The CCD procedure is an efficient method for developing multidimensional response surfaces by using second-order (quadratic) models with first-order interactions, without needing to use a complete 3-level factorial experiment. Five levels of each response variable are used, but not all combinations of these values appear in the design. The CCD is a composite of 3 separate components: the center point, the 8 corners of a cube forming a 2-level full factorial, and the star points in the center of each of the 6 faces. The inscribed CCD design results in 15 unique combinations of milking system vacuum, b-phase, and RVM, with the central point repeated 9 times to obtain an estimate of within-treatment variability. The 23 treatments were randomly assigned to the 23 test days (Table 1 ). The range of causal variables was chosen as a milking system vacuum of 42 to $53 \mathrm{kPa}$, b-phase of 200 to $800 \mathrm{~ms}$, and RVM of 16 to $30 \mathrm{kPa}$ (corresponding to average $\mathrm{LC}$ of 8 to $14 \mathrm{kPa}$ ). Because of the limitations of the pulsation controller, the minimum b-phase could not be implemented and a b-phase of $220 \mathrm{~ms}$ was used for the minimum treatment value.

The SAS mixed model procedure was used to fit the following general quadratic model (SAS Institute, 2008):

$$
\begin{gathered}
\text { PMF }=\text { vacuum }+ \text { vacuum } \\
2+\text { b-phase }+ \text { b-phase }^{2} \\
+\mathrm{RVM}+\mathrm{RVM}^{2}+(\text { vacuum } \times \text { b-phase }) \\
+(\text { vacuum } \times \text { RVM })+(\text { b-phase } \times \text { RVM }) .
\end{gathered}
$$


Table 1. Experimental conditions, run order, observed values, predicted values, and deviation of predicted from observed values ${ }^{1}$

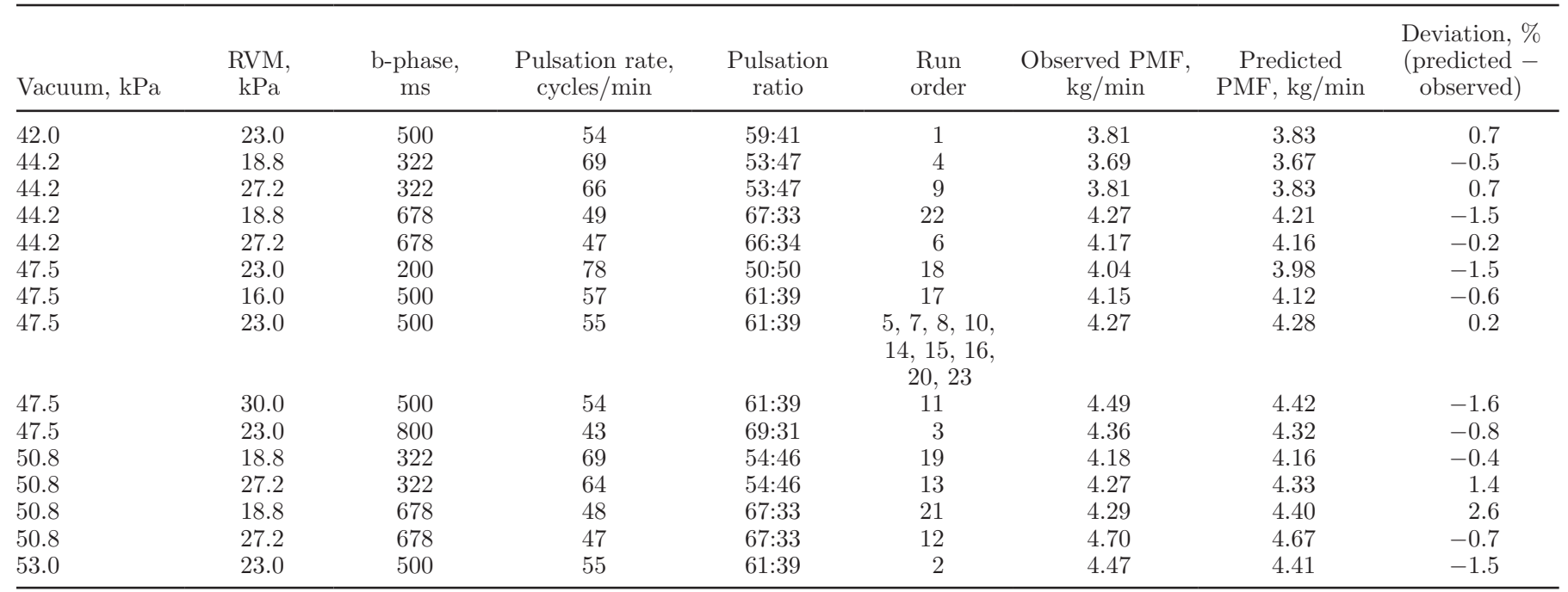

${ }^{1} \mathrm{RVM}=$ residual vacuum for massage PMF $=$ peak milk flow rate.

Cow was assigned as a random class variable as well as a repeated measure. Vacuum, b-phase, and RVM were fixed effects. Insignificant terms in the model were removed by backward elimination for $P$-values exceeding 0.05 to arrive at the final model.

\section{RESULTS}

The final model solution for PMF was

$$
\begin{aligned}
& \mathrm{PMF}=-4.38+(0.259 \times \text { vacuum })-(0.00264 \\
& \left.\times \text { vacuum }^{2}\right)+(0.00263 \times \text { b-phase })-\left(1.70 \times 10^{-6}\right. \\
& \left.\times \text { b-phase }{ }^{2}\right)-\left(0.00149 \times \mathrm{RVM}^{2}\right) \\
& +(0.00195 \times \text { vacuum } \times \text { RVM }) .
\end{aligned}
$$

Both linear and quadratic (curvature) terms for system vacuum and b-phase were significant. The quadratic term for RVM and the interaction between system vacuum and RVM were also significant. The overall fit of the model was very good, with an $\mathrm{R}^{2}$ value of 0.966 , and the deviation between the observed and predicted values showed no obvious trends (Table 1 and Figure 2). Peak milk flow rate increased continuously with increasing vacuum and with increasing b-phase over the entire range of experimental conditions (Figures 3, 4, and 5), with an overall increase of nearly $50 \%$ from the lowest to greatest predicted values (from b-phase of $220 \mathrm{~ms}$, vacuum of $42 \mathrm{kPa}, \mathrm{RVM}$ of $16 \mathrm{kPa}$, to b-phase of $800 \mathrm{~ms}$, vacuum of $53 \mathrm{kPa}$, RVM of 30 $\mathrm{kPa})$. The effects of both vacuum and b-phase on PMF were most pronounced at the lowest end of the predictive range and less pronounced at the upper end of the predictive range.
The final model solution for AMF was

$$
\begin{aligned}
& \mathrm{AMF}=2.95-(0.1168 \times \mathrm{RVM})+(0.00135 \\
& \left.\times \mathrm{RVM}^{2}\right)+(0.00131 \times \text { vacuum } \times \mathrm{RVM}) \\
& +\left(1.00 \times 10^{-5} \times \text { vacuum } \times \text { b-phase }\right) .
\end{aligned}
$$

The overall fit of the AMF model was also very good, with an $R^{2}$ value of 0.965 , and deviations between the observed and predicted values also showed no obvious trends. Interaction terms (vacuum $\times$ RVM) and

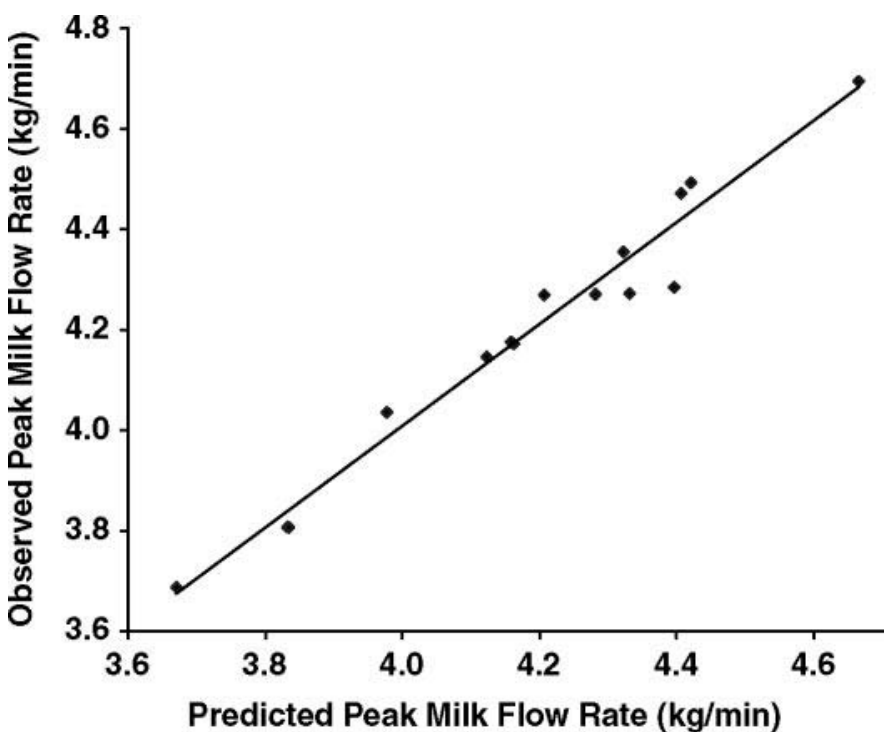

Figure 2. Observed values of peak milk flow rate from the central composite design points compared with the values predicted from the final model by using linear regression. 


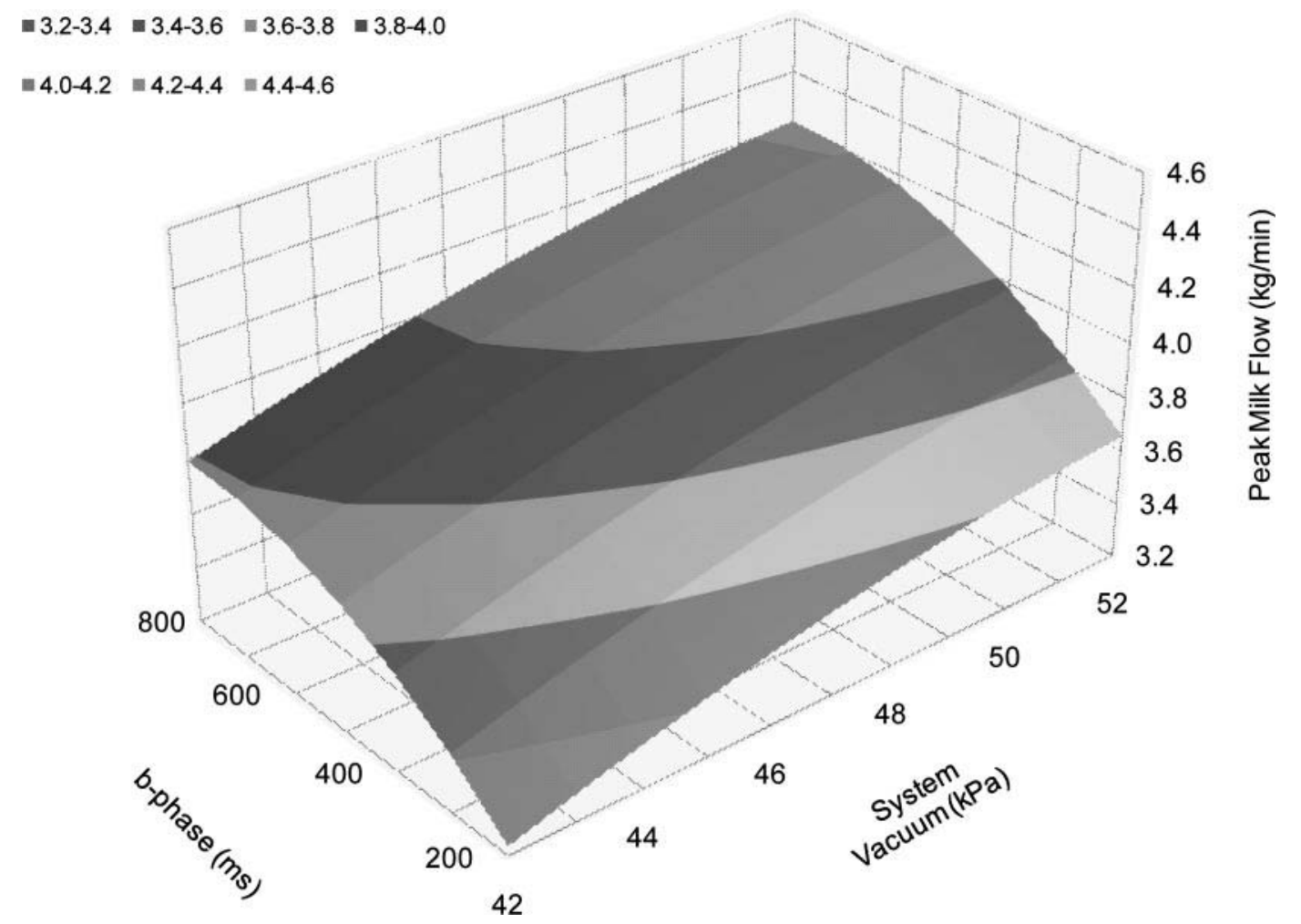

Figure 3. Predicted response surface for peak milk flow rate versus the b-phase and milking system vacuum for residual milking vacuum for massage of $16 \mathrm{kPa}$.

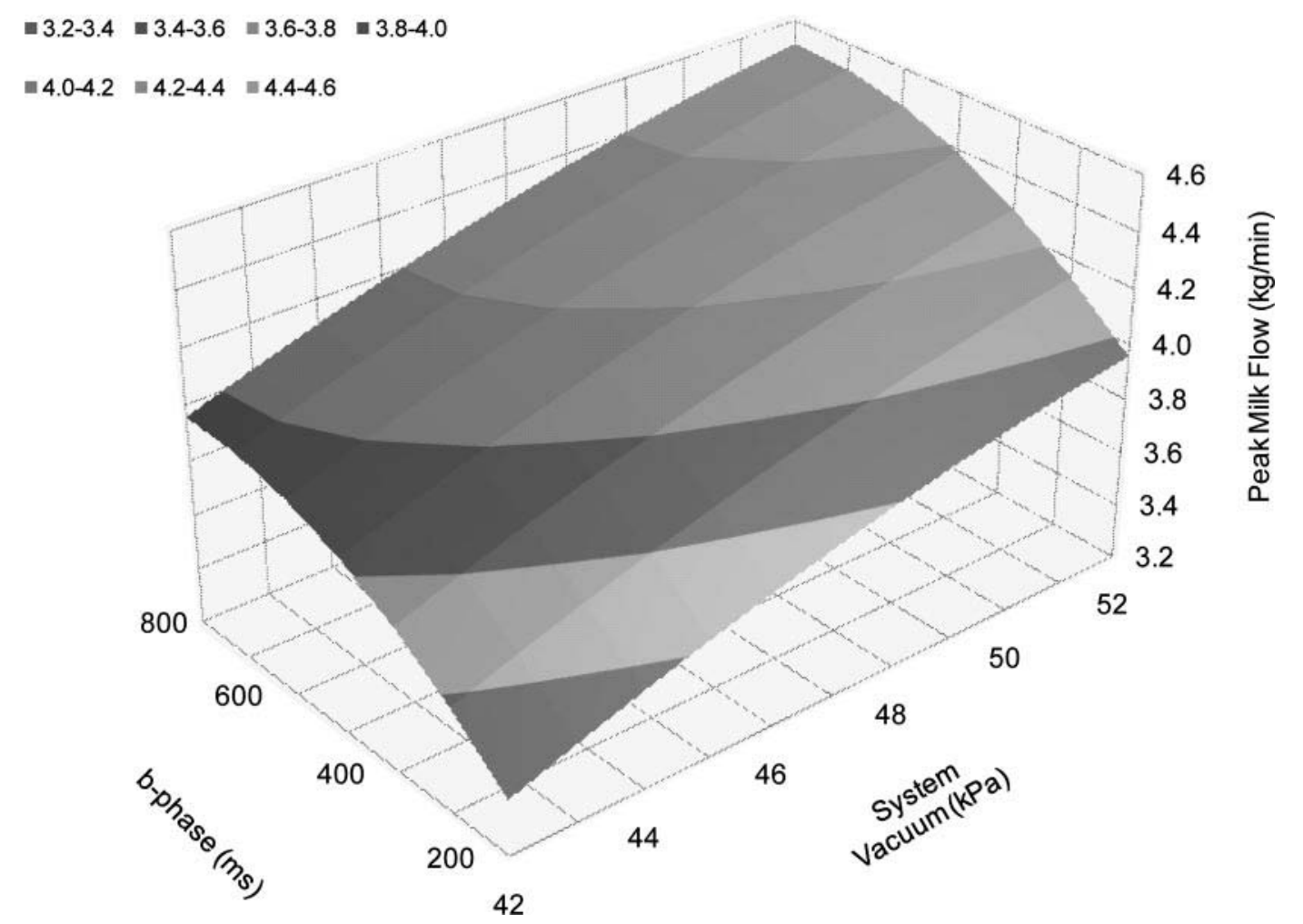

Figure 4. Predicted response surface for peak milk flow rate versus the b-phase and milking system vacuum for residual milking vacuum for massage of $23 \mathrm{kPa}$. 


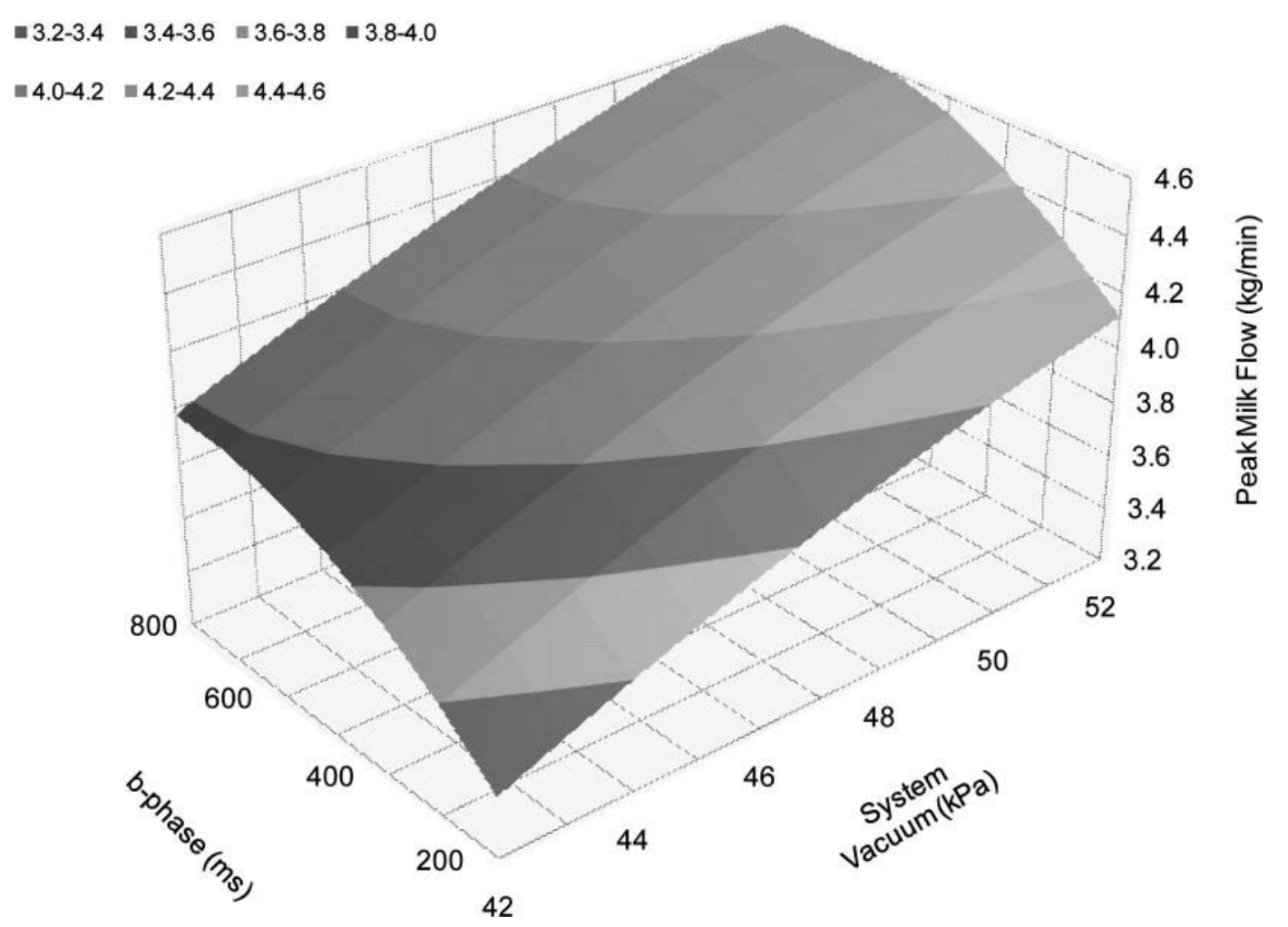

Figure 5. Predicted response surface for peak milk flow rate versus the b-phase and milking system vacuum for residual milking vacuum for massage of $30 \mathrm{kPa}$.

(vacuum $\times$ b-phase) were both significant in the $\mathrm{AMF}$ model. The predictive models indicated a much smaller response in AMF than PMF to vacuum, b-phase, and RVM (Figures 6 and 7). Average milk flow rate also increased continuously with increasing vacuum and with increasing b-phase, but with an overall increase of only $30 \%$ from the lowest to greatest predicted values (from b-phase of $220 \mathrm{~ms}$, vacuum of $42 \mathrm{kPa}$, RVM of $16 \mathrm{kPa}$, to b-phase of $800 \mathrm{~ms}$, vacuum of $53 \mathrm{kPa}, \mathrm{RVM}$ of $30 \mathrm{kPa}$ ). There was no effect of RVM on AMF at a vacuum of $42 \mathrm{kPa}$ and only a modest increase in $\mathrm{AMF}$ $(0.2 \mathrm{~kg} / \mathrm{min})$ at a vacuum of $53 \mathrm{kPa}$ when RVM was increased from 16 to $30 \mathrm{kPa}$ (Figure 7).

\section{DISCUSSION}

The physical principles of milk removal lead to the expectation that PMF would increase with increasing vacuum applied to the teat end (increased vacuum) and with increasing duration of the pulsation cycle devoted to milk extraction (increasing b-phase). Congestion of teat tissues surrounding the teat canal will act to decrease its effective diameter and reduce PMF. The degree of tissue congestion was expected to increase with increases in both vacuum and b-phase and to be moderated by increases in LC (achieved by increasing
RVM). The effect of RVM on PMF was used as an indication of the relative degree of teat tissue congestion produced by combinations of vacuum and b-phase. The effect on PMF of changing RVM from 16 to $30 \mathrm{kPa}$ was approximately $0.2 \mathrm{~kg} / \mathrm{min}$ at a vacuum of $42 \mathrm{kPa}$, whereas at a vacuum of $53 \mathrm{kPa}$, the effect of the same increase in RVM was approximately 3 times greater, or approximately $0.6 \mathrm{~kg} / \mathrm{min}$ (Figure 6). This suggests that a greater degree of teat tissue congestion occurred at greater vacuum, accounting for the larger effect of congestive relief supplied by greater LC.

The positive relationship between RVM (and therefore LC) and PMF in this study agrees with the findings of Williams et al. (1981) and is consistent with the physiological principle suggested by Mein et al. (2004) that the LC required to relieve congestion increases as the milking vacuum increases. The lack of significant interaction between RVM and b-phase and the moderate influence of RVM on PMF as b-phase was increased suggests that extending the b-phase had much less influence on the development of teat tissue congestion during one pulsation cycle than did increasing the vacuum.

The much smaller response of AMF than PMF to both vacuum and b-phase is an indication of the negative influence of extreme levels of vacuum and b-phase 
during the low-flow period of milking. When a quarter moves into the low-flow period of milking, the internal pressure is reduced from a slightly positive value, resulting from the standing column of milk in the udder cistern and pressure supplied by milk ejection, to a negative value (vacuum). The vacuum developed in the teat sinus increases during the course of the low-flow period of milking and results in congestion in the walls of the teat barrel. This congestion is not effectively relieved by the liner, which can collapse only around the end of the teat.

The effect of vacuum on PMF predicted from this study (using a b-phase of $500 \mathrm{~ms}$ and an RVM of 23 $\mathrm{kPa}$ ) was compared with previous studies (Figure 8). The slope was similar for all studies, whereas the magnitude of PMF from this study was comparable with those reported by Clough (1972), Spencer and Rogers (2004), and Spencer et al. (2007). The very early study by Stewart and Schultz (1958) and the more recent study by Rasmussen and Madsen (2000) reported much lower PMF rates than in this study. There are several possible causes for the lower PMF values reported in these studies: 1) The interval over which PMF was measured in our study was $11.2 \mathrm{~s}$, whereas these studies may have used longer measurement intervals. 2) These studies used high-level milk lines, which produce a greater system-to-claw vacuum drop than low-level milk lines during the peak flow period. 3) The effective diameter of teat canals of the cows used in these studies may have been smaller than in our study. Holstein cows in the United States have been selected for faster

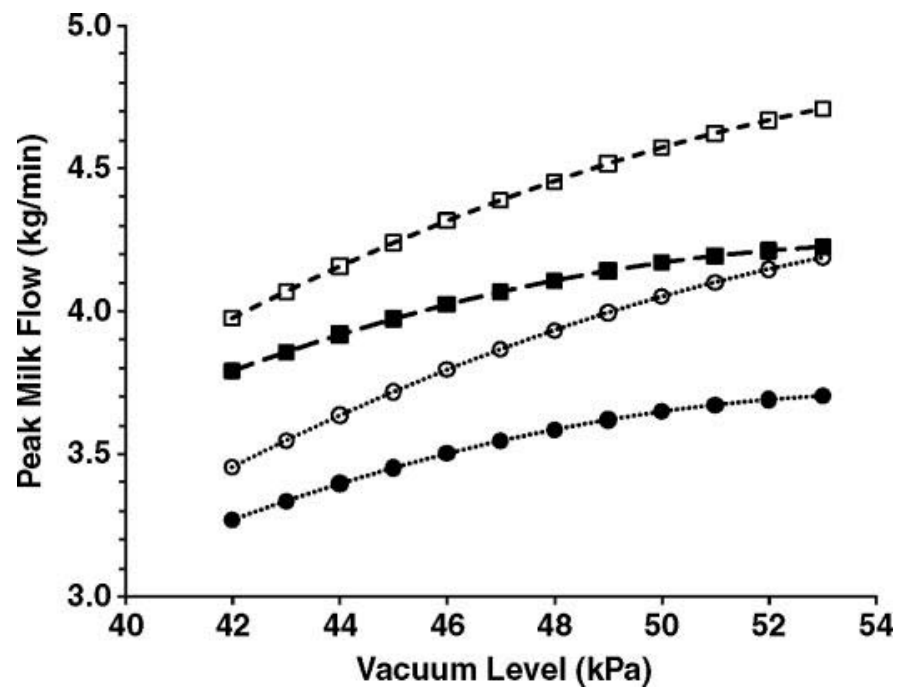

Figure 6. Predicted relationship between peak milk flow rate and vacuum for selected conditions of the b-phase and residual vacuum for massage $(\mathrm{RVM})$ : b-phase $=220 \mathrm{~ms}, \mathrm{RVM}=16 \mathrm{kPa}(\bullet)$; b-phase $=$ $220 \mathrm{~ms}, \mathrm{RVM}=30 \mathrm{kPa}(\mathrm{O})$; b-phase $=800 \mathrm{~ms}, \mathrm{RVM}=16 \mathrm{kPa}(\mathbf{\square})$; b-phase $=800 \mathrm{~ms}, \mathrm{RVM}=30 \mathrm{kPa}(\square)$. milking, which may account for differences between the cows used in this study and those used by Stewart and Schultz (1958). There may also be differences in the genetics of US Holsteins and the cows used in the Danish study by Rasmussen and Madsen (2000).

The relationship between the b-phase and PMF predicted from this study (with a vacuum of $47.5 \mathrm{kPa}$ and an RVM of $23 \mathrm{kPa}$ ) was also compared with previous studies (Figure 9). The b-phase duration from previous studies was approximated from the reported pulsation rate and ratio. Peak milk flow rate was comparable across all studies for b-phase, in the range of 500 to 600 ms. Spencer and Rogers (2004) and Spencer et al. (2007) reported an interaction between pulsation ratio and vacuum, whereas in this study, we did not find an interaction between vacuum and b-phase. These interactions may have resulted from a reduction in the d-phase of pulsation when the b-phase was increased by increasing the pulsation ratio while holding the pulsation rate constant. The decoupling of changes in the b-phase and d-phase of pulsation also likely accounts for the reduced slope of the PMF/b-phase relationship in this study as compared with previous studies. The reduction in PMF at a b-phase of $750 \mathrm{~ms}$ reported by Clough (1972) is likely the result of a severely shortened d-phase at the greatest pulsation ratio (Williams et al., 1981; Hamann and Mein, 1996).

It is important to put these PMF results into the broader perspective of milking management. The objective of this experiment was to gain a better understanding of the physiological effects of machine milking.

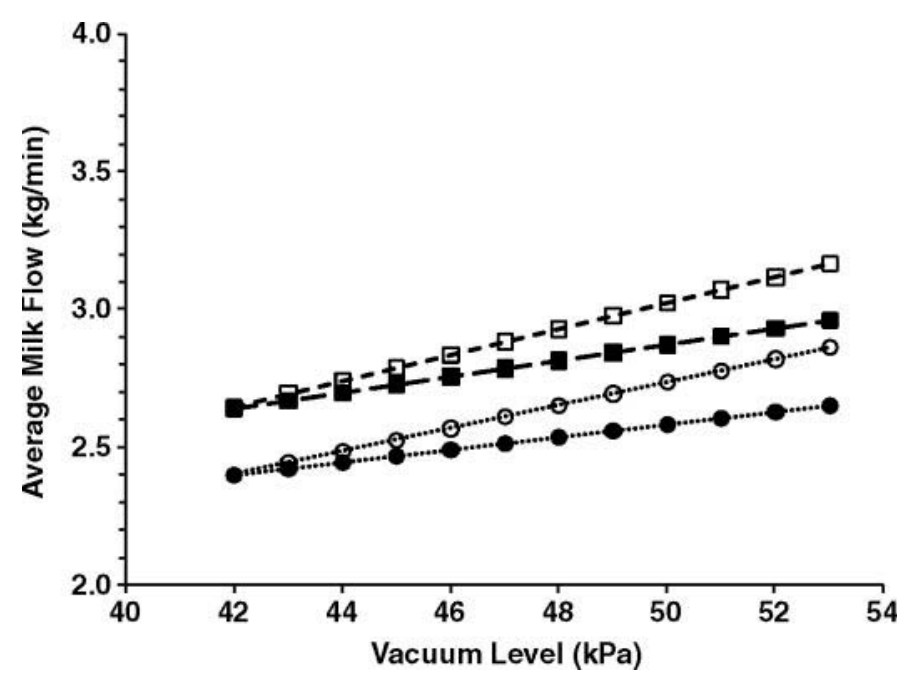

Figure 7. Model results predicting the relationship between average milk flow rate and vacuum for selected conditions of the b-phase and residual vacuum for massage $(\mathrm{RVM})$ : $\mathrm{b}$-phase $=220 \mathrm{~ms}$, $\mathrm{RVM}=$ $16 \mathrm{kPa}(\bullet)$; b-phase $=220 \mathrm{~ms}, \mathrm{RVM}=30 \mathrm{kPa}(\bigcirc)$; b-phase $=800 \mathrm{~ms}$, $\mathrm{RVM}=16 \mathrm{kPa}(\mathbf{\square})$; b-phase $=800 \mathrm{~ms}, \mathrm{RVM}=30 \mathrm{kPa}(\square)$. 


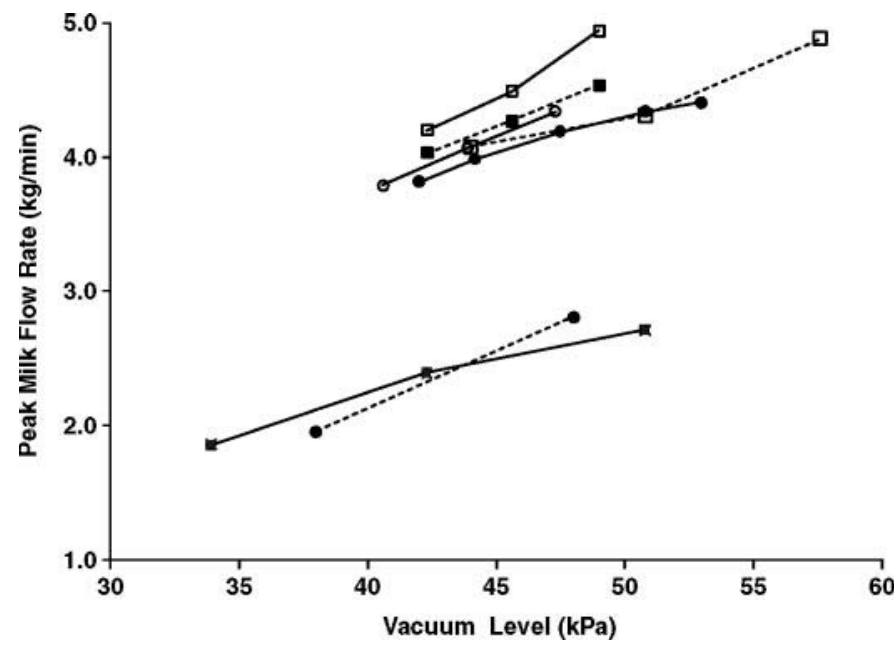

Figure 8. Effect of vacuum on peak milk flow rates from this study and previous studies: (-๑) this study; (-口-) Stewart and Schultz, 1958); ( $\square-$ - Spencer and Rogers, 2004 [lower residual vacuum for massage (RVM)]; (----) Spencer and Rogers, 2004 (greater RVM); (一○-) Spencer et al. 2007); (-- $\square--)$ Clough, 1972; (--•--) Rassmussen and Madsen, 2000.

We used a much wider range of milking conditions than those common in practice. The choice of vacuum, bphase, and LC in practice is a balance between milking quickly, gently, and completely. This experiment did not include direct measures of teat tissue reactions or teat skin condition in either the short or long term. This experiment applied extreme conditions for only one milking, and it was apparent that cow comfort during milking and teat tissue condition after milking were compromised under some of the conditions. Liner compression is positively correlated with vacuum for any individual liner (Bade et al., 2007), and hyperkeratosis is positively correlated with LC (Mein et al., 2003). If vacuum is increased in an effort to increase milking speed, increased hyperkeratosis will likely result. Postmilking openness of the teat canal also appears to be related to vacuum, LC, milking duration, and teat congestion (Mein et al., 2001) so that increasing the vacuum may also increase this risk. The increases in AMF with increasing vacuum and b-phase were not as large as the corresponding increases in PMF. Increasing the vacuum, b-phase, and LC above currently accepted practice could produce slightly faster milking (AMF); however, these settings would likely produce increased hyperkeratosis, increased postmilking teat-end congestion, and possibly more open teat ends after milking.

\section{CONCLUSIONS}

Peak milk flow rate increased continuously with increasing vacuum, b-phase, and RVM over the wide range

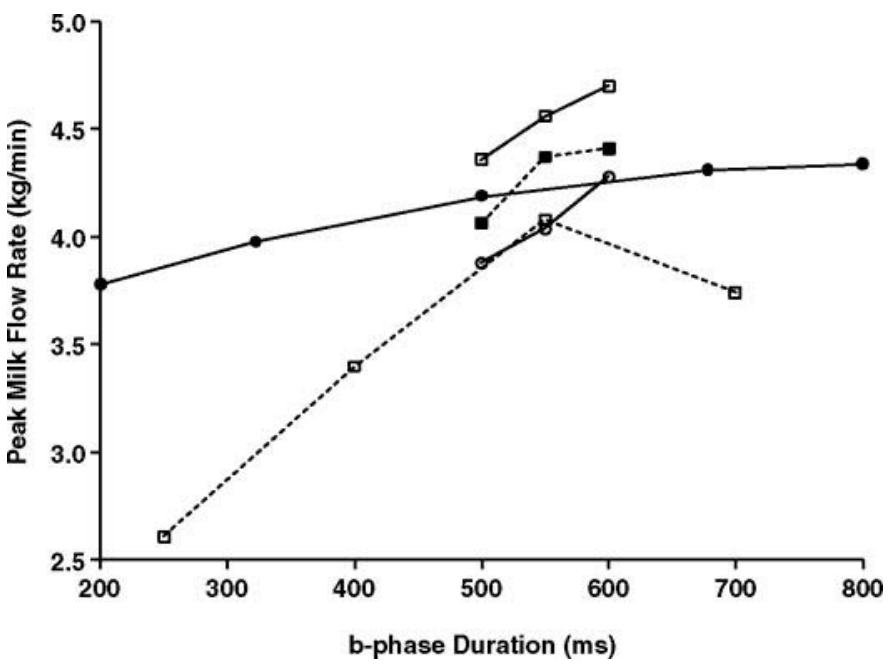

Figure 9. Effect of b-phase duration on peak milk flow rates from this study and previous studies: (- - - ) this study; ( $\square-$ Spencer and Rogers, 2004 [lower residual vacuum for massage (RVM)], (----) Spencer and Rogers, 2004 (greater RVM); (一○—) Spencer et al., 2007; (-- $\square--)$ Clough, 1972.

of values tested in this study (no relative maximum was attained); however, the magnitude of increase in PMF decreased as the value of all 3 of these causal variables increased. The interaction between vacuum and RVM and the lack of interaction between b-phase and RVM is an indication that for a corresponding increase in PMF, increasing the b-phase produced less teat-end tissue congestion than did increasing the vacuum. The effect of LC on PMF increased as milking vacuum increased, supporting the physical principle that the LC required to relieve teat tissue congestion increases as milking vacuum is increased. The increases in AMF with increasing vacuum and b-phase were not as large as the increases in PMF.

\section{REFERENCES}

Bade, R. D., D. J. Reinemann, and G. A. Mein. 2007. Sources of variability in compressive load applied to bovine teats. Pages 212 213 in 45th Natl. Mastitis Counc. Ann. Mtg. Proc., Atlanta, GA. Natl. Mastitis Counc. Inc., Madison, WI.

Baxter, E. S., P. M. Clarke, F. H. Dodd, and A. S. Foot. 1950. Factors affecting the rate of machine milking. J. Dairy Res. 17:117-127.

Clough, P. A. 1972. Pipeline milking machines and milking systems. Agric. Eng. 27:17-24.

Davis, M. A., D. J. Reinemann, and G. A. Mein. 2000. Effect of liner age on milking characteristics. Pages $89-90$ in 38th Natl. Mastitis Counc. Ann. Mtg. Proc., Atlanta, GA. Natl. Mastitis Counc. Inc., Madison, WI.

Gleeson, D. E., E. J. O'Callaghan, and M. V. Rath. 2004. Effect of liner design, pulsator setting, and vacuum level on bovine teat tissue changes and milking characteristics as measured by ultrasonography. Ir. Vet. J. 57:289-296.

Hamann, J. 1990. Effect of machine milking on teat end condition with special emphasis on infection risk. World Rev. Anim. Prod. 25:9-12. 
Hamann, J., and G. A. Mein. 1996. Teat thickness changes may provide biological test for effective pulsation. J. Dairy Res. 63:179-189.

Hamann, J., G. A. Mein, and S. Wetzel. 1993. Teat tissue reactions to milking: Effects of vacuum level. J. Dairy Sci. 76:1040-1046.

Mein, G. A., F. Neijenhuis, W. F. Morgan, D. J. Reinemann, J. E. Hillerton, J. R. Baines, I. Ohnstad, M. D. Rasmussen, L. Timms, J. S. Britt, R. Farnsworth, N. Cook, and T. Hemling. 2001. Evaluation of bovine teat condition in commercial dairy herds: 1 . Non-infectious factors. Pages 347-351 in Am. Assoc. Bovine Pract.Natl. Mastitis Counc. Int. Symp. Mastitis and Milk Quality Proc., Vancouver, British Columbia, Canada. University of Waikato, Ruakura, New Zealand.

Mein, G. A., D. J. Reinemann, E. O'Callaghan, and I. Ohnstad. 2004. Where the rubber meets the teat and what happens to milking characteristics. Bull. Int. Dairy Fed. No. 388/2004. Pages 28-34 in Proc. IDF World Dairy Summit 2003: 100 Years with Liners and Pulsators in Machine Milking. Int. Dairy Fed./Fed. Int. Laiterie, Brussels, Belgium.

Mein, G. A., D. M. Williams, and D. J. Reinemann. 2003. Effects of milking on teat-end hyperkeratosis: 1 . Mechanical forces applied by the teatcup liner and responses of the teat. Pages 114-123 in 41st Natl. Mastitis Counc. Ann. Mtg. Proc., Fort Worth, TX. Natl. Mastitis Counc. Inc., Madison, WI.

Mein, G. A., D. M. Williams, and C. C. Thiel. 1987. Compressive load applied by the teatcup liner to the bovine teat. J. Dairy Res. 54:327-337.

Neijenhuis, F., G. H. Klungel, and H. Hogeveen. 2001. Recovery of cow teats after milking as determined by ultrasonographic scanning. J. Dairy Sci. 84:2599-2606.

National Institute of Standards and Technology. 2006. SEMATECH e-Handbook of Statistical Methods, US Commerce Department Technology Administration. http://www.itl.nist.gov/div898/ handbook/ Accessed July 18, 2006.
Rasmussen, M. D., and N. P. Madsen. 2000. Effects of milkline vacuum, pulsator airline vacuum, and cluster weight on milk vield, teat condition, and udder health. J. Dairy Sci. 83:77-84.

SAS Institute. 2008. Statistical Analysis System. SAS Inst. Inc., Cary, $\mathrm{NC}$.

Smith, V. R., and W. E. Petersen. 1946. The effect of increasing the negative pressure and widening of the vacuum-release ratio on the rate of removal of milk from the udder. J. Dairy Res. 29:45-53.

Spencer, S. B., and G. W. Rogers. 2004. Optimization of milkingmachine liners. Pages 75-80 in Bull. Intl. Dairy Fed.: 100 Years with Liners and Pulsators in Machine Milking. Int. Dairy Fed./ Fed. Int. Laiterie, Brussels, Belgium.

Spencer, S. B., J. W. Shin, G. W. Rogers, and J. B. Cooper. 2007. Short Communication: Effect of vacuum and ratio on the performance of a monoblock silicone milking liner. J. Dairy Sci. 90:1725-1728.

Stewart, W. E., and L. H. Schultz. 1958. The rate of machine milking of dairy cows. II. Effect of vacuum and pulsation rate. J. Dairy Sci. $41: 849-856$.

Thomas, C. V., D. K. Force, D. H. Bremel, and S. Strasser. 1991. Effects of pulsation ratio, pulsation rate, and teatcup liner design on milking rate and milk production. J. Dairy Sci. 74:12431249 .

Vinitchaikul, P., and W. Suriyasathaporn. 2007. Comparisons of teat structure changes after milking between farms with high and low bulk somatic cell counts. J. Dairy Sci. 90(Suppl. 1):607.

Williams, D. M., and G. A. Mein. 1982. Physical and physiological factors affecting milk flowrate from the bovine teat during machine milking. Pages 42-74 in Proc. Dairy Prod. Pasture Conf., Hamilton, New Zealand. University of Waikato, Ruakura, New Zealand.

Williams, D. M., G. A. Mein, and M. R. Brown. 1981. Biological responses of the bovine teat to milking: Information from measurements of milk flow-rate within single pulsation cycles. J. Dairy Res. 48:7-21. 